\title{
Capped semiconductor colloids: Synthesis and photochemistry of CdS capped $\mathrm{SnO}_{2}$ nanocrystallites
}

\author{
ROBERT KENNEDY ${ }^{\mathrm{a}}$, IGNACIO MARTINI ${ }^{\mathrm{a}}$, \\ GREG HARTLAND ${ }^{a}$ and PRASHANT V KAMAT ${ }^{b *}$ \\ "Department of Chemistry, University of Notre Dame, Notre Dame, IN 46556, USA \\ ${ }^{b}$ Radiation Laboratory, University of Notre Dame, Notre Dame, IN 46556, USA \\ e-mail: Hartland.1@nd.edu \\ e-mail:Kamat.1@nd.edu
}

\begin{abstract}
Cds-capped $\mathrm{SnO}_{2}\left(\mathrm{CdS} @ \mathrm{SnO}_{2}\right)$ and $\mathrm{SiO}_{2}\left(\mathrm{CdS} @ \mathrm{SiO}_{2}\right)$ colloids of $50-80 \AA$ in diameter have been prepared in aqueous medium. Significant quenching of CdS emission is observed in the CdS@ $\mathrm{SnO}_{2}$ system as the electrons are injected from the excited $\mathrm{CdS}$ shell into the $\mathrm{SnO}_{2}$ core. Photoinduced charge separation in this system also results in transient bleaching in the $450 \mathrm{~nm}$ region. Picosecond laser flash photolysis studies of composite semiconductor nanoclusters that highlight the effect of the metal oxide core on the photophysical properties of the outer CdS shell are described.
\end{abstract}

Keywords. CdS-capped $\mathrm{SnO}_{2}$ and $\mathrm{SiO}_{2}$ colloids; composite semiconductor systems; emission properties; molecular devices.

\section{Introduction}

Recently, considerable interest is focused on developing composite semiconductor materials with coupled capped geometries ${ }^{1,2}$. This approach is based on the principle of combining two semiconductors with different energy levels ${ }^{3,4}$. The charge separation that can be achieved with composite semiconductor systems makes these systems attractive for designing molecular devices and integrated chemical systems for solar energy conversion. For example, coupled semiconductor particles have been shown to improve the photocurrent generation in thin particle films of $\mathrm{TiO}_{2}-\mathrm{CdS}^{5-8}, \mathrm{ZnO}-\mathrm{CdS}^{9}$ and $\mathrm{TiO}_{2} / \mathrm{CdSe}^{10,11}$. Such coupled semiconductor thin films not only extend the photoresponse of large bandgap semiconductors but also rectify the flow of photogenerated charge carriers ${ }^{10}$ and improve the efficiency of dye sensitization ${ }^{12}$. Composite semiconductor systems such as $\mathrm{TiO}_{2} / \mathrm{CdS}, \mathrm{TiO}_{2} / \mathrm{SnO}_{2}, \mathrm{TiO}_{2} / \mathrm{WO}_{3}, \mathrm{TiO}_{2} / \mathrm{MnO}_{2}$, $\mathrm{TiO}_{2} / \mathrm{SiO}_{2}, \mathrm{TiO}_{2} / \mathrm{ZrO}_{2}$ and $\mathrm{TiO}_{2} / \mathrm{WO}_{3}$ have also been beneficial in enhancing the rates of photocatalytic degradation processes ${ }^{13-21}$.

The capped nanoclusters essentially have a core-shell geometry, while in coupled systems the two semiconductor nanoclusters are in contact with each other. The principle of charge separation in capped and coupled semiconductor systems is illustrated in scheme 1. While the mechanism of charge separation in a capped semiconductor system is similar to that in a coupled semiconductor system, the interfacial charge transfer or charge collection at this multicomponent semiconductor

* For correspondence

Contribution No. 3961 from the Notre Dame Radiation Laboratory, USA 


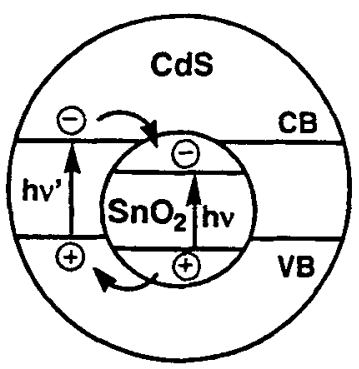

(a)

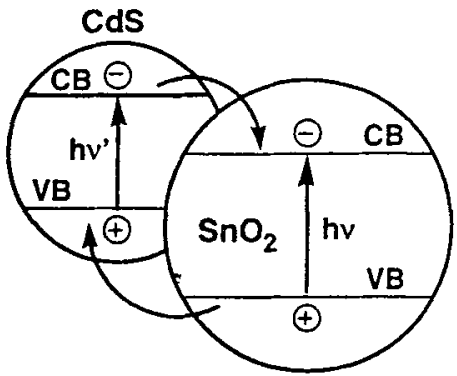

(b)

Scheme 1 Principle of charge separation in semiconductor heterostructures: (a) Capped (or core-shell) geometry and (b) Coupled geometry. Electrons accumulate at the conduction band (CB) of $\mathrm{SnO}_{2}$ while holes at the valence band (VB) of CdS.

system is significantly different. Only one of the charge carriers is accessible at the surface in a capped semiconductor system, thus making selective charge transfer possible at the semiconductor/electrolyte interface. The other charge carrier (e.g., the electron of Scheme 1) gets trapped within the inner semiconductor particle and is not readily accessible. In a coupled semiconductor system both holes and electrons are accessible for selective oxidation and reduction processes on different particle surfaces.

The photophysical and photochemical properties of a variety of coupled and capped type semiconductor nanoclusters have been investigated in several laboratories. These

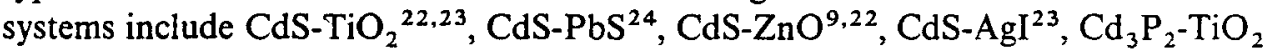
and $\mathrm{Cd}_{3} \mathrm{P}_{2}-\mathrm{ZnO}^{25}, \mathrm{ZnO}-\mathrm{ZnS}^{26}, \mathrm{ZnO}-\mathrm{ZnSe}^{27}, \mathrm{AgI}-\mathrm{Ag}_{2} \mathrm{~S}^{28}, \mathrm{SnO}_{2}-\mathrm{TiO}_{2}{ }^{29}$ and $\mathrm{CdS} / \mathrm{HgS}^{30,31}$. In our earlier studies, we have shown that excitation of $\mathrm{CdS}$ colloids coupled with a metal oxide colloids such as $\mathrm{ZnO}^{9}$ or $\mathrm{TiO}_{2}{ }^{23}$ results in the injection of electrons into the lower lying conduction band of the metal oxide. The charge injection process in these systems was shown to occur within the pulse duration of 20 ps. Recent studies have indicated that such an inter-particle electron transfer occurs within $500 \mathrm{fs}-2 \mathrm{ps}^{32,33}$.

Brus and his coworkers have demonstrated the feasibility of controlling the nucleation and growth of $\mathrm{CdSe}$ on $\mathrm{ZnS}$ and $\mathrm{ZnS}$ on CdSe quantum crystallites ${ }^{34}$. Recently, Eychmüller and his coworkers ${ }^{30.35}$ have demonstrated interesting fluorescence properties of CdS colloids capped with $\mathrm{HgS}$. Elucidation of the energetic structure and charge carrier dynamics of this system led to the conclusion that its electronic properties are significantly different from the sum of the separate particles. Optical properties of $\mathrm{PbS}$ coated CdS particles have also been investigated ${ }^{36.37}$ Development of such semiconductors is interesting, since by changing the thickness of the shell and the particle radius, the overlap of the wavefunctions and bandgap can be altered. Theoretical models for the quantum confinement in semiconductor heterostructures have been developed by Haus and coworkers ${ }^{38}$.

In view of the many interesting features of this core-shell type semiconductor system we have synthesized $\mathrm{CdS}$ capped $\mathrm{SnO}_{2}$ colloids for investigating photoinduced charge transfer processes. In the present paper, our initial studies describing the preparation and photophysical properties are presented. 


\section{Experimental}

\subsection{Materials}

$\mathrm{SnO}_{2}$ colloidal suspension in water $(18 \%$, particle size $30-50 \AA)$ was obtained from Alfa Chemicals and used without further purification. Colloidal silica (\#2326, 14.5\%, $50 \AA, p H 9.0$ ) was a gift sample from NALCO. All other chemicals were analytical reagents and used as supplied. Absorption spectra were recorded with a Perkin Elmer 3840 Diode Array Spectrophotometer. Emission spectra were recorded with SLM 8000 spectrofluorometer.

\subsection{TEM.measurements}

A small drop of the colloidal suspension was applied to carbon-coated copper grids before using them for transmission electron microscopic examination. Particle sizes were determined from the photographs taken at a magnification of $200000-300000 \mathrm{X}$ using a Hitachi $\mathrm{H} 600$ transmission electron microscope. The pictures were further magnified by photographic enlargement.

\subsection{Picosecond laser flash photolysis}

Picosecond laser flash photolysis experiments were performed with $355 \mathrm{~nm}$ laser pulses from a mode-locked, Q-switched Continuum YG-501 DP Nd;YAG laser system (output $2-3 \mathrm{~mJ} /$ pulse, $\sim 18 \mathrm{ps}$ pulse width). The white light continuum picosecond probe pulse was generated by passing the fundamental output through a $\mathrm{D}_{2} \mathrm{O} / \mathrm{H}_{2} \mathrm{O}$ solution. The output was fed to a spectrograph (HR-320, ISDA Instruments, Inc.) with fiber optic cables and was analyzed with a dual diode array detector (Princeton Instruments, Inc.) interfaced with an IBM-AT computer. The details of the experimental setup and its operation are described elsewhere ${ }^{39,40}$. Time zero in these experiments corresponds to the end of the excitation pulse.

\section{Results and discussion}

\subsection{Synthesis of CdS capped $\mathrm{SnO}_{2}$ colloids}

The method employed in the preparation of capped colloids involves adsorption of $\mathrm{Cd}^{2+}$ ions on to the inner core semiconductor colloid followed by the exposure of the solution to $\mathrm{H}_{2} \mathrm{~S}$. A typical procedure involves addition of $0.1 \mathrm{ml}$ of $0.1 \mathrm{M} \mathrm{Cd}\left(\mathrm{ClO}_{4}\right)_{2}$ to a $25 \mathrm{ml}$ aqueous suspension of $0.04 \% \mathrm{SiO}_{2}$ or $\mathrm{SnO}_{2}$ colloids $(p \mathrm{H} \sim 10)$ in an airtight glass vessel. The suspension in the glass vessel was cooled to $\sim 273 \mathrm{~K}$ and was then subjected to vacuum for a brief period of time to remove dissolved air. $25 \mathrm{ml} \mathrm{of} \mathrm{H}_{2} \mathrm{~S}$ was then injected into the vessel. The solution slowly turned yellow as CdS precipitated on to the $\mathrm{SiO}_{2}$ or $\mathrm{SnO}_{2}$ core. After waiting for 2 min the excess $\mathrm{H}_{2} \mathrm{~S}$ was pumped off by subjecting the glass vessel to vacuum. The suspension was stable for several days. By controlling the concentration of $\mathrm{Cd}^{2+}$ it is possible to vary the thickness of the $\mathrm{CdS}$ shell. These capped colloids will be referred as $\mathrm{SnO}_{2} @ \mathrm{CdS}$ and $\mathrm{SiO}_{2} @ \mathrm{CdS}$ respectively in the following discussion.

\subsection{Characterization of capped colloids}

a. Absorption spectra. The absorption spectra of aqueous suspensions of capped colloids are compared with those of native colloids in figures $1 \mathrm{~A}$ and B. The CdS 

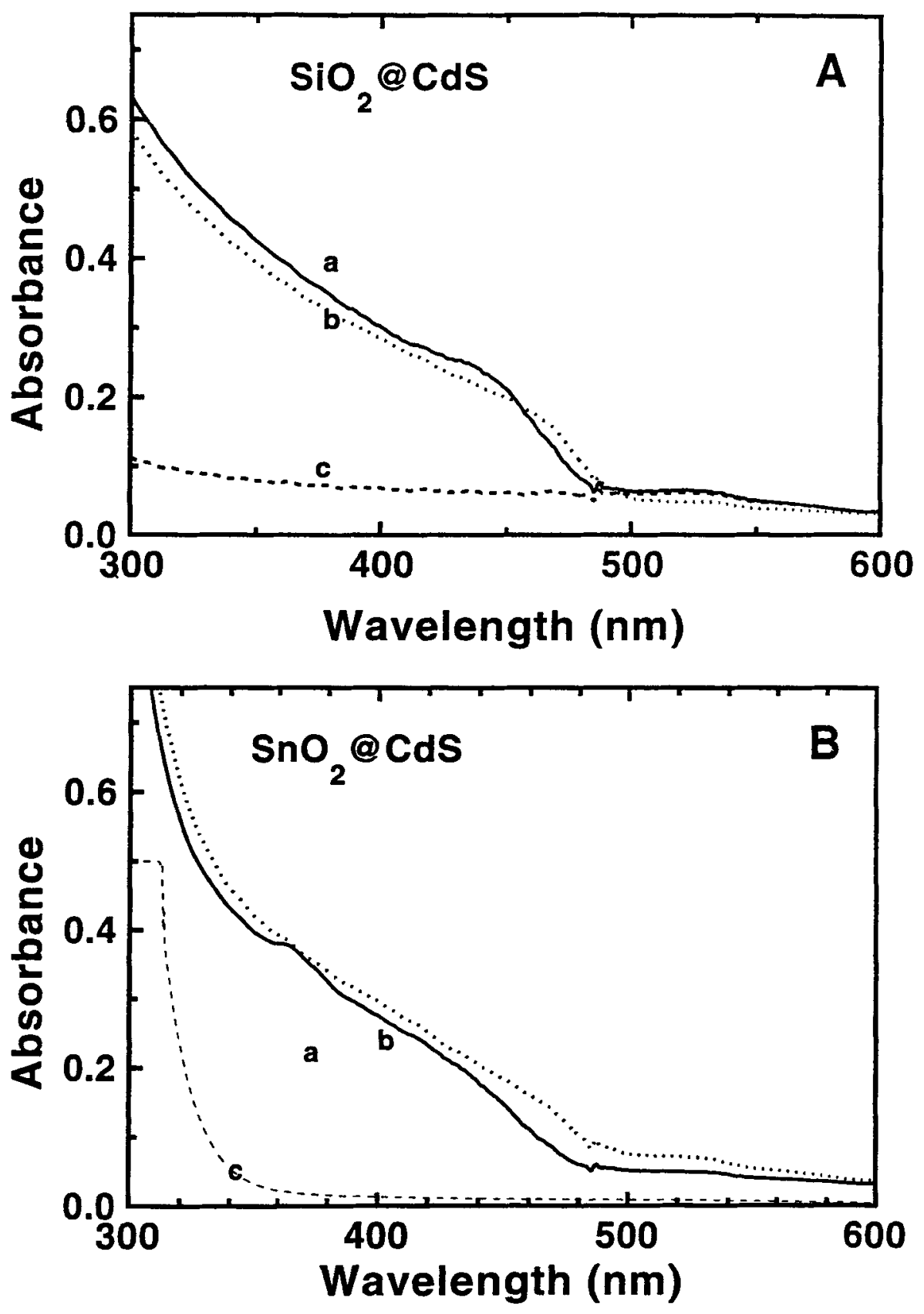

Figure 1. A. Absorption spectra of aqueous suspensions of $\mathrm{SiO}_{2} @ \mathrm{CdS}$ colloids (a) immediately after preparation and (b) after 3 days of aging. The spectrum of blank $\mathrm{SiO}_{2}$ colloidal suspension is also shown (spectrum c).

B. Absorption spectra of aqueous suspensions of $\mathrm{SnO}_{2} @ \mathrm{CdS}$ colloids (a) immediately after preparation and (b) after $3 \mathrm{~h}$ of aging. The spectrum of blank $\mathrm{SnO}_{2}$ colloidal suspension is also shown (spectrum c). 

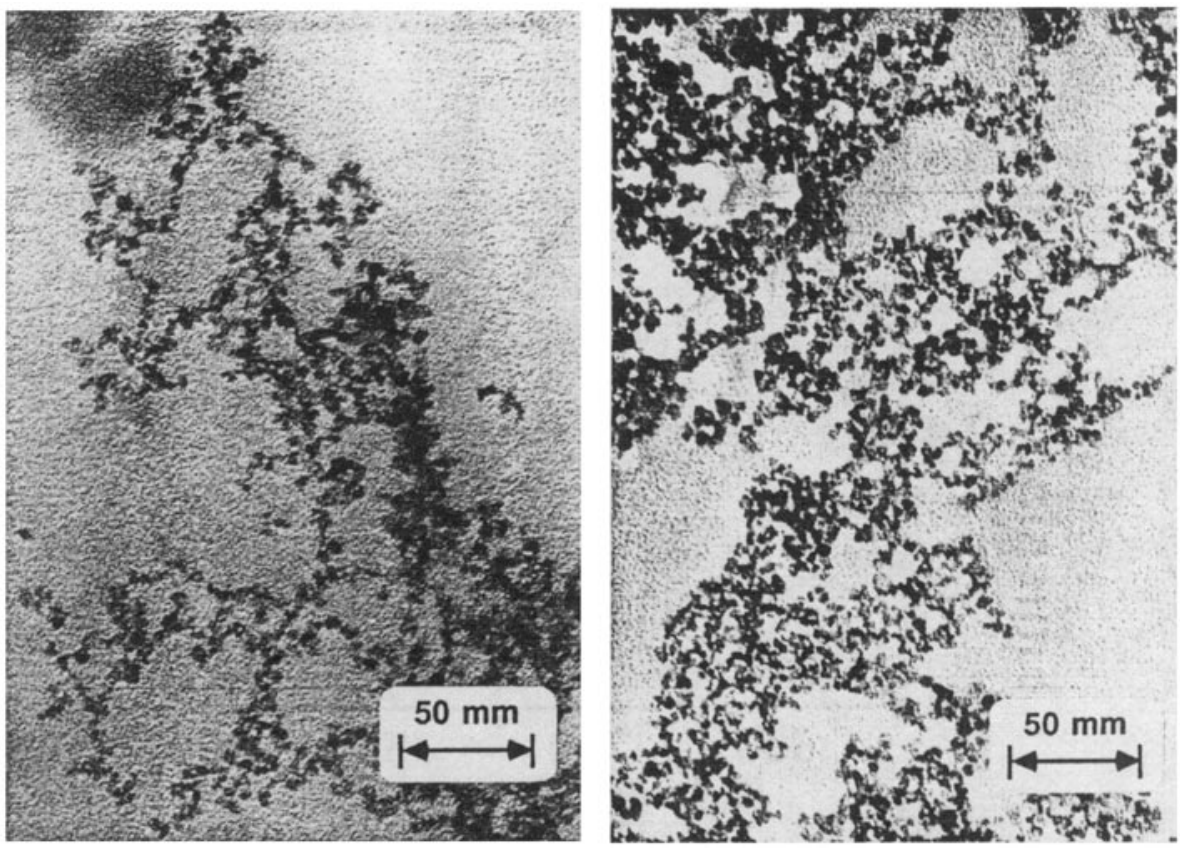

Figure 2. Transmission electron micrograph of $\mathrm{SnO}_{2}$ colloids $(560000 \mathrm{X})$ and $\mathrm{SnO}_{2} @ \mathrm{CdS}$ colloids $(530,000 \mathrm{X})$.

capped colloids exhibit significant absorption in the visible. The onset of absorption of these colloids is at $480 \mathrm{~nm}$ which is close to the CdS bandgap of $2.5 \mathrm{eV}$. The change in the absorption of the aged solutions only exhibit a small shift in the onset absorption $(5-10 \mathrm{~nm})$ which we attribute to a small growth in the particle diameter.

b. Transmission electron microscopy. Figure 2 shows the transmission electron microscopy (TEM) pictures of $\mathrm{SnO}_{2}$ and $\mathrm{SnO}_{2} @ \mathrm{CdS}$ colloids. $\mathrm{SnO}_{2}$ colloids have particle diameters in the range of 50-70 $\AA$. $\mathrm{SnO}_{2} @ \mathrm{CdS}$ colloids are nearly spherical with very small change in the particle diameter. This shows that the $\mathrm{CdS}$ layer coated onto the $\mathrm{SnO}_{2}$ core is relatively thin. We expect its thickness to be in the range of 5-10 $\AA$. The pictures of capped colloid samples do not show two different particle sizes, thus, the possibility of forming $\mathrm{CdS}$ particles away from the $\mathrm{SnO}_{2}$ surface is ruled out. Similar observations were also made with $\mathrm{CdS}$ capped $\mathrm{SiO}_{2}$ colloids. The growth of the $\mathrm{CdS}$ layer on $\mathrm{SiO}_{2}$ (particle diameter 50-70 $\AA$ ) was less than $10 \AA$. Relatively small polydispersity observed from the micrographs in figure 2 indicates that the capping of $\mathrm{CdS}$ is quite uniform over the oxide particles.

c. Emission spectra. Emission measurements of semiconductor colloids provides a convenient means of probing charge trapping, as well as interfacial charge transfer processes $^{41-43}$. Coadsorption of ions from solution often dictates the nature of surface states which influences trapping of the photogenerated charge carriers. The nature of surface defect sites influences the emission properties of semiconductor colloids. It would therefore be interesting to see what effect the oxide core has on the emission properties of $\mathrm{CdS}$. The emission spectra of $\mathrm{SnO}_{2} @ \mathrm{CdS}$ colloids and $\mathrm{SiO}_{2} @ \mathrm{CdS}$ are shown in figures 3 and 4 . The freshly prepared suspensions of both samples show red 


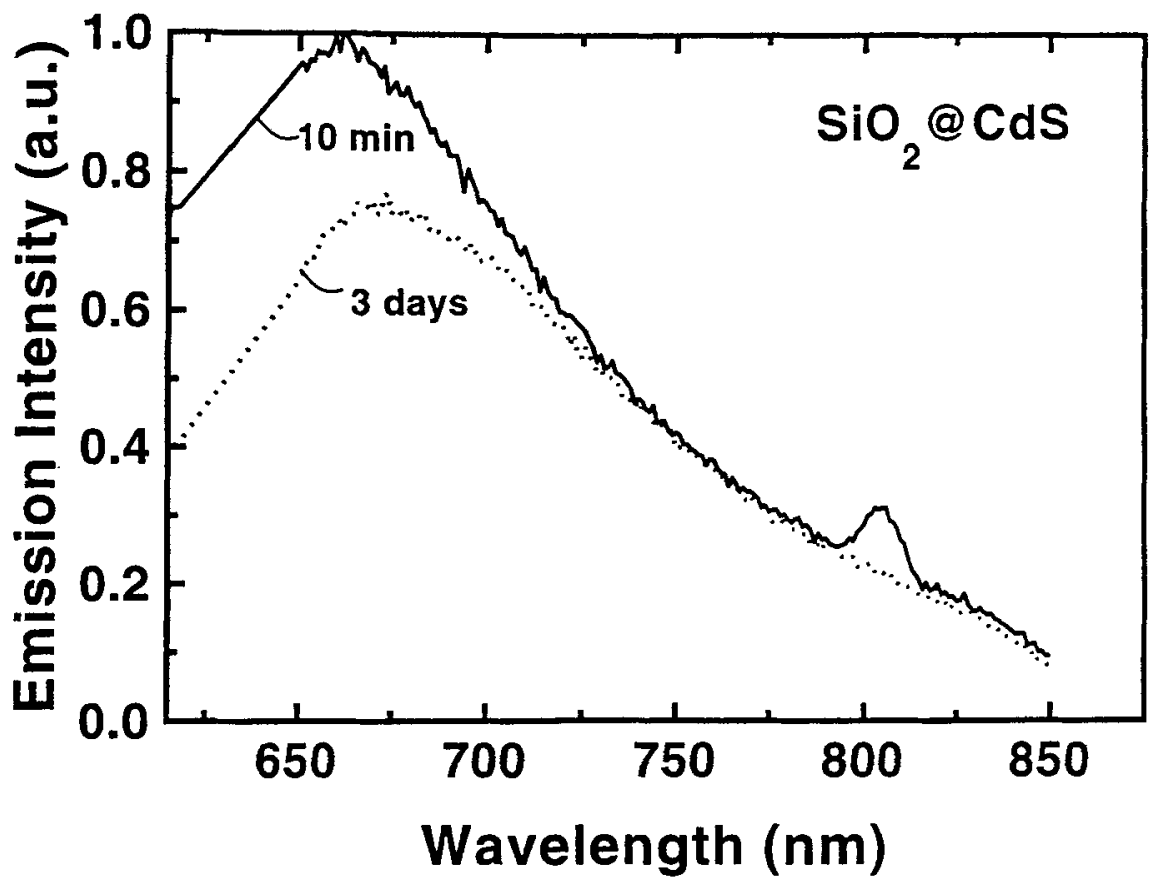

Figure 3. Emission spectra of aqueous suspensions of $\mathrm{SiO}_{2} @ \mathrm{CdS}$ colloids (a) $10 \mathrm{~min}$ after preparation and (b) after 3 days of aging. The spectra were recorded at room temperature $(296 \mathrm{~K})$ with $400 \mathrm{~nm}$ excitation and were corrected for instrument response.

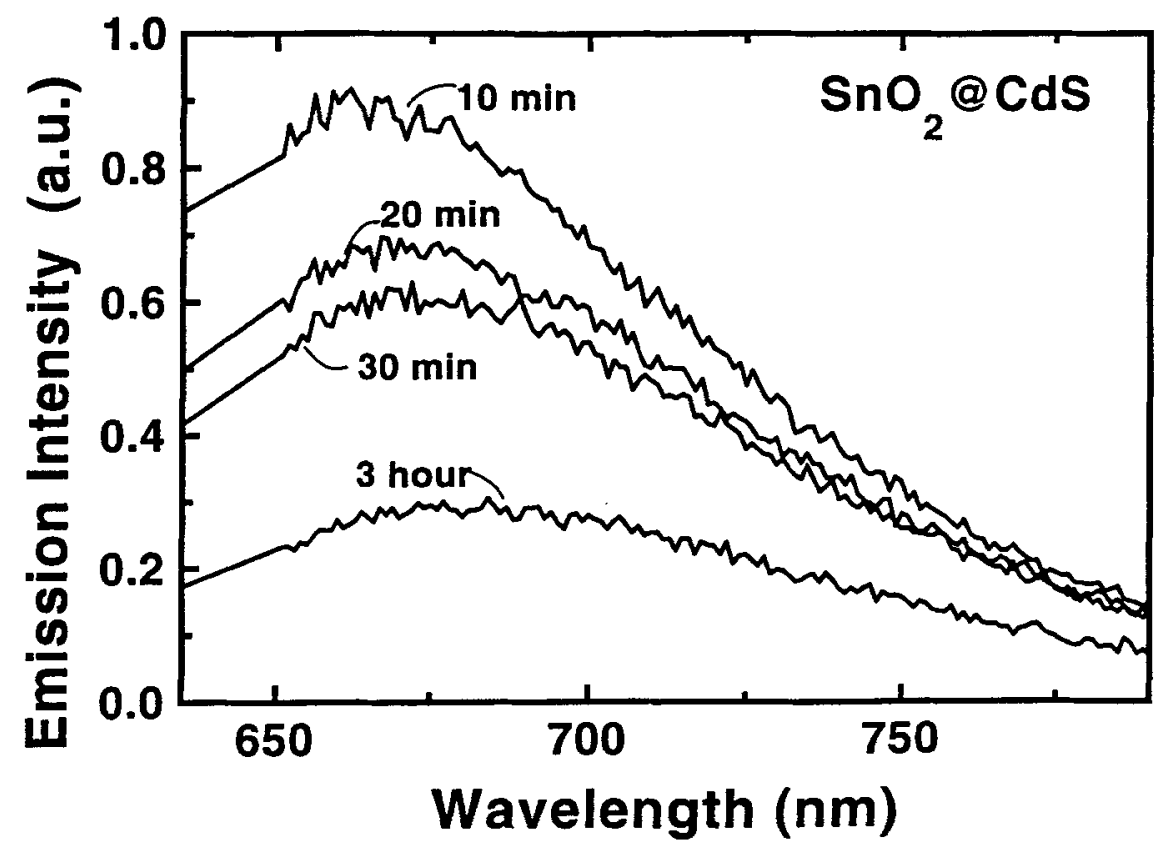

Figure 4. Emission spectra of aqueous suspensions of $\mathrm{SnO}_{2} @ \mathrm{CdS}$ colloids recorded at time intervals: (a) $10 \mathrm{~min}$, (b) $20 \mathrm{~min}$, (c) $30 \mathrm{~min}$ and (d) after $3 \mathrm{~h}$ after its preparation. The spectra were recorded at room temperature $(296 \mathrm{~K})$ with $400 \mathrm{~nm}$ excitation and were corrected for instrument response. 
emission with a maximum around $650 \mathrm{~nm}$. This red emission mainly arises from the sulfur vacancy and its maximum is dependent on the particle size. Upon aging for $3 \mathrm{~h}$ $\mathrm{SnO}_{2} @ \mathrm{CdS}$ colloids show more than $70 \%$ quenching in the emission yield. There is no noticeable change in the emission maximum or the absorption spectrum which rules out particle growth during this period. Under similar aging conditions $\mathrm{SiO}_{2} @ \mathrm{CdS}$ do not show any noticeable changes in the emission yield. Aging for an additional period of 3 days produced a further $20 \%$ decrease in the emission yield (figure 3 ). This decrease is also accompanied by a small red-shift $(15-20 \mathrm{~nm})$ in the emission maximum, thus indicating a small growth in the particle size during this extended aging process.

The difference in quenching behavior suggests that the inner oxide core plays a significant role in controlling the emission properties of the outer $\mathrm{CdS}$ layer. $\mathrm{SiO}_{2}$ being an insulator does not directly interact with $\mathrm{CdS}$ shell. On the other hand $\mathrm{SnO}_{2}$ is a large bandgap semiconductor with its conduction band ( $E_{C B}=-0.2 \mathrm{~V}$ vs NHE) less negative than the conduction band of $\mathrm{CdS}\left(\mathrm{E}_{\mathrm{CB}}=-1.2 \mathrm{~V}\right.$ vs NHE). Photoexcitation of $\mathrm{CdS}$ thus results in charge separation as the electrons are injected into the inner core of $\mathrm{SnO}_{2}$. Such a photoinduced charge separation has been observed earlier for composite semiconductor systems such as $\mathrm{TiO}_{2}$ capped $\mathrm{SnO}_{2}$ colloids ${ }^{29}$ and $\mathrm{TiO}_{2} / \mathrm{CdS}$ coupled colloids $^{22,23}$. Another interesting aspect is the aging period that is necessary to establish the interaction between the $\mathrm{SnO}_{2}$ core and CdS shell. We attribute it to the formation of small individual crystallites of CdS in the early stages of precipitation. During the short aging period these CdS crystallites grow on the oxide surface to form a uniform layer, thereby maximizing the interaction with the inner core of $\mathrm{SnO}_{2}$. A pictorial illustration that shows the growth of the CdS shell on the $\mathrm{SnO}_{2}$ core is shown in scheme 2 .
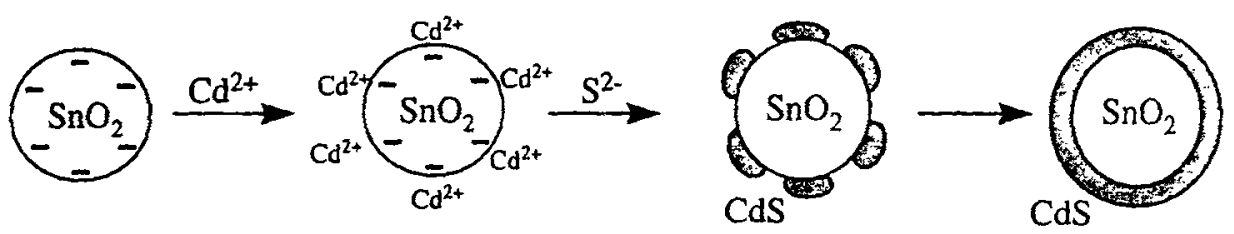

Scheme 2. Chemical precipitation of a $\mathrm{CdS}$ layer on to a $\mathrm{SnO}_{2}$ nanocluster.

The emission results illustrated in figures 3 and 4 can be understood as follows. Upon bandgap excitation, the initial charge separation occurs at the CdS layer. This is followed by charge recombination and or charge separation. In the case of $\mathrm{SiO}_{2} @ \mathrm{CdS}$ the $\mathrm{SiO}_{2}$ core has little influence on the emission behavior of the $\mathrm{CdS}$ shell.

$$
\mathrm{SiO}_{2} @ \mathrm{CdS} \stackrel{\mathrm{hv}}{\longrightarrow} \mathrm{SiO}_{2} @ \mathrm{CdS}(\mathrm{e} . . . . \mathrm{h}) \longrightarrow \mathrm{SiO}_{2} @ \mathrm{CdS}+\mathrm{h} v^{\prime} .
$$

On the other hand, the emission quenching in $\mathrm{SnO}_{2} @ \mathrm{CdS}$ colloids indicates lesser charge recombination as the photogenerated electrons and holes quickly diffuse in opposite directions to accumulate at the $\mathrm{SnO}_{2}$ core and the CdS shells respectively,

$$
\mathrm{SnO}_{2} @ \mathrm{CdS} \stackrel{\text { hv }}{\longrightarrow} \mathrm{SnO}_{2} @ \mathrm{CdS}(\mathrm{e} . . . . \mathrm{h}) \longrightarrow \mathrm{SnO}_{2}\left(\mathrm{e}_{\mathrm{t}} @ \mathrm{CdS}\left(\mathrm{h}_{\mathrm{t}}\right)\right. \text {. }
$$

The quick transfer of electrons to the $\mathrm{SnO}_{2}$ core thus prevents the recombination of charge carriers within the CdS layer. The electron transfer between the two 
semiconductors can be understood on the basis of band energetics. The energetics of the conduction $\left(\mathrm{E}_{\mathrm{CB}\left(\mathrm{SnO}_{2}\right)}=-0.0 \mathrm{~V}\right.$ and $\mathrm{E}_{\mathrm{CB}(\mathrm{CdS})}=-1.0 \mathrm{~V}$ vs NHE at $\left.p \mathrm{H} 7\right)$ and valence bands $\left(\mathrm{E}_{\mathrm{VB}\left(\mathrm{SnO}^{2}\right)}=+3.5 \mathrm{~V}, \mathrm{E}_{\mathrm{VB}(\mathrm{CdS})}=1.5 \mathrm{~V}\right.$ vs NHE at $p \mathrm{H}$ 7) of these two semiconductor layers favor charge separation within the capped semiconductor system.

\subsection{Picosecond laser flash photolysis experiments.}

Time-resolved transient absorption spectra recorded after the $355 \mathrm{~nm}$ laser pulse excitation of $\mathrm{SiO}_{2} @ \mathrm{CdS}$ and $\mathrm{SnO}_{2} @ \mathrm{TiO}_{2}$ colloids are shown in figures 5 and 6 respectively. Both these spectra show intense bleaching with a maximum around $480 \mathrm{~nm}$. This bleaching observed near the band edge of CdS essentially shows the shift in its absorption following photoinduced charge separation.

The nonlinear optical property of metal chalcogenide nanoclusters has been the topic of many recent investigations ${ }^{44-52}$. In these studies explanations for the observed transient bleaching were provided on the basis of various photophysical processes, viz., dynamic Burstein effect, charge trapping and Stark effects. In a composite semiconductor system this process is more complicated as the inner semiconductor core can influence the photophysical properties of the outer layer of metal chalcogenide. Also the newly evolved electronic wave functions of the semiconductor composite can influence the overall photobleaching ${ }^{35}$. Excitation of $\mathrm{SnO}_{2} @ \mathrm{CdS}$ colloids results in the transfer of electrons to the inner core and the trapped holes on the outer surface.

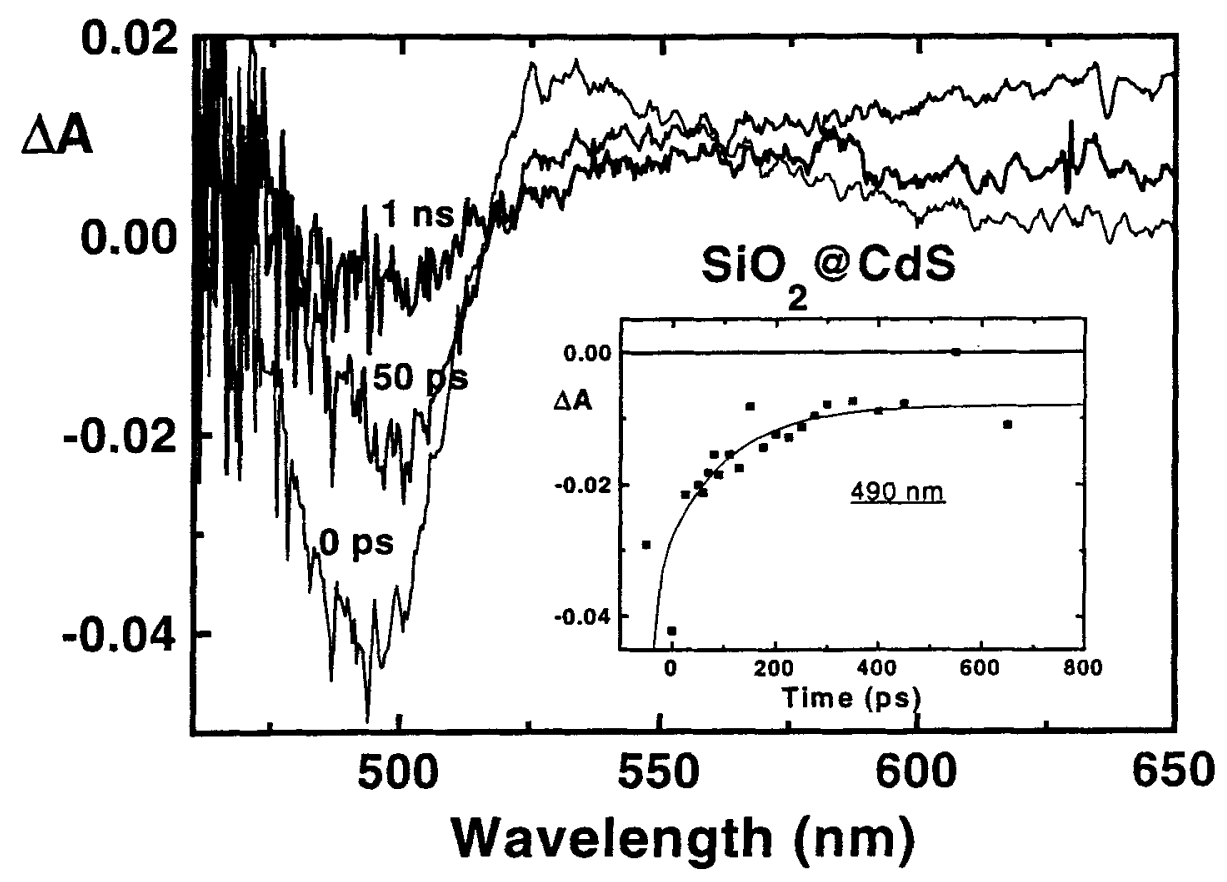

Figure 5. Time-resolved transient absorption spectra recorded after $355 \mathrm{~nm}$ laser excitation (1.5 mJ,18 ps pulse width) excitation of a $\mathrm{SiO}_{2} @ \mathrm{CdS}$ colloidal suspension in water (deaerated with $\mathrm{N}_{2}$ ). The inset shows the transient bleaching recovery at $490 \mathrm{~nm}$. 


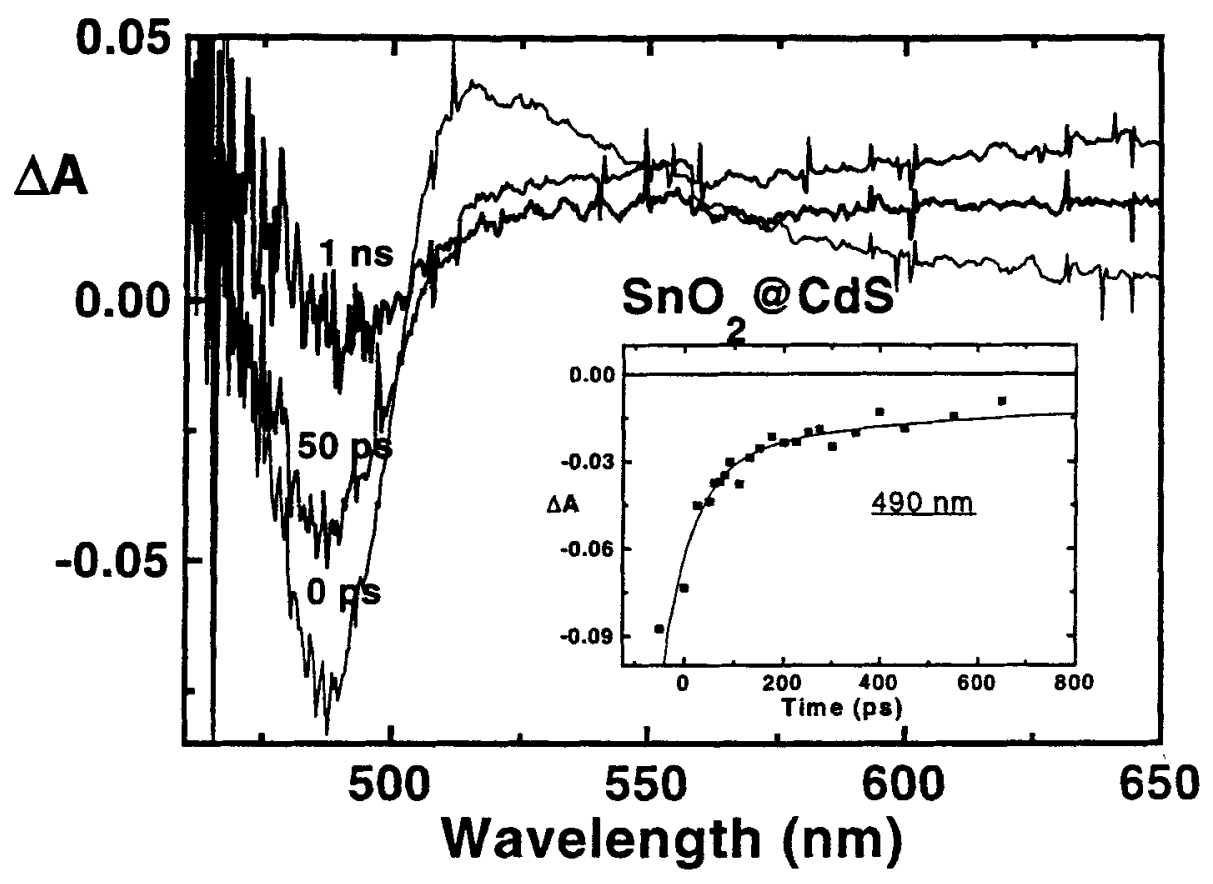

Figure 6. Time-resolved transient absorption spectra recorded after $355 \mathrm{~nm}$ laser excitation (1.5 mJ, 18 ps pulse width) excitation of a $\mathrm{SnO}_{2} @ \mathrm{CdS}$ colloidal suspension in water (deaerated with $\mathrm{N}_{2}$ ). The inset shows the transient bleaching recovery at $490 \mathrm{~nm}$.

The intense electric field created as a result of this charge separation causes a shift in the band edge of CdS. This effect which is usually explained on the basis of the Stark effect has also been observed by depositing excess charge on CdS colloids or by applying an electric field to $\mathrm{CdSe} \mathrm{film}^{51}$.

The magnitude of the bleaching in the case of $\mathrm{SnO}_{2} @ \mathrm{CdS}$ is approximately two times higher than that of $\mathrm{SiO}_{2} @ \mathrm{CdS}$. We attribute this enhanced bleaching to the increased charge separation in $\mathrm{SnO}_{2} @ \mathrm{CdS}$ colloids. The prompt appearance of the transient bleaching indicates that this process is completed within the leading edge of the laser pulse (pulse width of $18 \mathrm{ps}$ ). The insets in figure 5 and 6 show the recovery of the bleaching indicating the time scale with which charges are recombined. Most of this recovery is completed within a time period of $1 \mathrm{~ns}$. The residual bleaching represents long-term charge separation and/or irreversible changes resulting from the photoexcitation. These preliminary transient absorption studies indicate the possible use of capped semiconductor colloids for non-linear optical applications. We are presently carrying out femtosecond transient absorption measurements to resolve the photophysical events that occur during the transient bleaching processes in composite semiconductor nanoclusters.

\section{Conclusions}

In this study we have made an effort to investigate photophysical properties of chemically synthesized semiconductor heterostructures such as $\mathrm{SnO}_{2} @ \mathrm{CdS}$. 
By controlling the methods of preparation it is possible to tailor the photocatalytic property of such composite semiconductor nanoclusters. Their ability to carry out redox processes with greater efficiency and selectivity than the single component systems has made them potential candidates for the conversion and storage of solar energy, and in the mineralization of chemical pollutants. These systems have potential applications in designing novel microheterogeneous assemblies, microelectronics and chemical sensors.

\section{Acknowledgements}

PVK acknowledges the support of the Office of the Basic Energy Sciences of the US Department of Energy. RK and GVH acknowledge the support of the Faculty Research Program of the University of Notre Dame.

\section{References}

1. Kamat P V and Vinodgopal K 1996 In Fine Particles Science and Technology: From Micro to Nanoparticles (ed.) E. Pelizzetti, Kluwer Academic Publishers, Dordrecht, The Netherlands, p. 303.

2. Kamat P V 1996 In Nanocrystalline semiconductor materials (eds) P V Kamat and D Meisel, Elsevier Science, Amsterdam

3. Nozik A J 1977 Appl. Phys. Lett., 30567

4. Gruzdkov Y A, Savinov E N, Korolkov V V and Parmon VN 1988 React. Kinet. Catal. Lett., 36395

5. Gerischer H and Lübke M 1986 J. Electroanal. Chem. Interfacial Electrochem, 204225

6. Vogel R, Pohl K and Weller H 1990 Chem. Phys. Lett., 174241

7. Kohtani S, Kudo A and Sakata T 1993 Chem. Phys. Lett., 206166

8. Vogel R, Hoyer P and Weller H 1994 J. Phys. Chem., 983183

9. Hotchandani S and Kamat P V 1992 J. Phys. Chem., 966834

10. Liu D and Kamat P V 1993 J. Phys. Chem., 9710769

11. Liu D and Kamat P V 1993 J. Electroanal. Chem. Interfacial Electrochem, 347451

12. Hotchandani S and Kamat P V 1992 Chem. Phys. Lett., 191320

13. Serpone N, Borgarello E and Grätzel M 1984 J. Chem. Soc., Chem. Commun, 342

14. Serpone N, Maruthamuthu P, Pichat P, Pelizzetti E and Hidaka H $1995 \mathrm{~J}$. Photochem. Photobiol., A: Chem., 85247

15. Vinodgopal K and Kamat P V 1995 Environ. Sci. Technol., 29841

16. Vinodgopal K, Bedja I and Kamat P V 1996 Chem. Mater., 82180

17. Tennakone K, Iieperuma O A , Bandara J M S and Kiridena W C B 1992 Semicond. Sci. Technol., 7423

18. Papp J, Soled S, Dwight K and Wold A 1994 Chem. Mater., 6496

19. Anderson C and Bard A J 1995 J. Phys. Chem., 999882

20. Fu X, Clark L A, Yang Q and Anderson M A 1996 Environ. Sci. Technol., 30647.

21. Trimoto T, Ito S, Kuwabata S and Yoneyama H 1996 Environ. Sci. Technol., 301275

22. Spanhel L, Weller H and Henglein A 1987 J. Am. Chem. Soc., 1096632

23. Gopidas K R, Bohorquez M and Kamat P V 1990 J. Phys. Chem., 946435

24. Zhou H S, Honma I and Komiyama H 1993 J. Phys. Chem., 97895

25. Spanhel L, Henglein A and Weller H 1987 Ber. Bunsenges. Phys. Chem., 911359

26. Rabani J 1989 J. Phys. Chem., 937707

27. Kamat P V and Patrick B 1992 J. Phys. Chem., 966829

28. Henglein A, Gutierrez M, Weller H, Fojtik A and Jirkovsky J 1989 Ber. Bunsenges. Phys. Chem., 93593

29. Bedja I and Kamat P V 1995 J. Phys. Chem., 999182

30. Haesselbarth A, Eychmueller A, Eichberger R, Giersig M, Mews A and Weller H $1993 \mathrm{~J}$. Phys. Chem., 975333 
31. Kamalov V F, Little R, Logunov S L and El-Sayed M A 1996 J. Phys. Chem., 1006381

32. Kietzmann R, Willig F, Weller H, Vogel R, Nath D N, Eichberger R, Liska P and Lehnert J 1991 Mol. Cryst. Liq. Cryst., 194169

33. Evans J E, Springer K W and Zhang J Z 1994 J. Chem. Phys., 1016222

34. Kortan A R, Hull R, Opila R L, Bawendi M G, Steigerwald M L, Carroll P J and Brus L E $1990 \mathrm{~J}$. Am. Chem. Soc., 1121327

35. Eychmueller A, Vobmeyer T, Mews A and Weller H 1994 J. Lumin., 58223

36. Zhou H S, Sasahara H, Honma I, Komiyama H and Haus J W 1994 Chem. Mater., 61534

37. Zhou H S, Honma I, Haus J W, Sasabe H and Komiyama H 1996 J. Lumin., 7021

38. Haus J W, Zhou H S, Honma I and Komiyama H 1993 Phys. Rev., 471359

39. Ebbesen T W 1988 Rev. Sci. Instrum., 591307

40. Kamat P V, Ebbesen T W, Dimitrijevic N M and Nozik A J 1989 Chem. Phys. Lett., 157384

41. Rossetti R and Brus L 1982 J. Phys. Chem., 864470

42. Chestnoy N, Harris T D, Hull R and Brus L E 1986 J. Phys. Chem., 903393

43. Kamat P V, Dimitrijevic N M and Fessenden R W 1987 J. Phys. Chem., 91396

44. Haase M, Weller H and Henglein A 1988 J. Phys. Chem., 924706

45. Henglein A, Kumar A, Janata E and Weller H 1986 Chem. Phys. Lett., 132133

46. Banyai L and Koch S W 1986 Phys. Rev. Lett., 572722

47. Liu C and Bard A J 1989 J. Phys. Chem., 933232

48. Kamat P V, Dimitrijevic N M and Nozik A J 1989 J. Phys. Chem., 932873

49. Hilinski E F, Lucas P A and Wang Y 1988 J. Chem. Phys., 893435

50. Wang Y, Suna A, McHugh J, Hilinski E F, Lucas P A and Johnson R D 1990 J. Chem. Phys., 926927

51. Colvin V L and Alivisatos A P 1992 J. Chem. Phys., 97730.

52. Luangdilok C, Lawless D and Meisel D 1996 In Fine Particles Science and Technology (ed.) E Pelizzatti, Kluwer Academic Publishers, Boston, p. 457 